\title{
Defying c-Abl signaling circuits through small allosteric compounds
}

\author{
Stefania Gonfloni * \\ Department of Biology, University of Rome Tor Vergata, Rome, Italy
}

\section{Edited by:}

Andreas Zanzoni, Inserm TAGC UMR1090, France

Allegra Via, Sapienza University, Italy

\section{Reviewed by:}

Oliver Hantschel, École

Polytechnique Fédérale de

Lausanne, Switzerland

Stephan Grzesiek, University of

Basel, Switzerland

*Correspondence:

Stefania Gonfloni, Department of

Biology, University of Rome Tor

Vergata, Via della Ricerca

Scientifica, 00133 Rome, Italy

email: stefania.gonfloni@

uniroma2.it
Many extracellular and intracellular signals promote the c-Abl tyrosine kinase activity. $\mathrm{c}$-Abl in turn triggers a multitude of changes either in protein phosphorylation or in gene expression in the cell. Yet, c-Abl takes part in diverse signaling routes because of several domains linked to its catalytic core. Complex conformational changes turn on and off its kinase activity. These changes affect surface features of the c-Abl kinase and likely its capability to bind actin and/or DNA. Two specific inhibitors (ATP-competitive or allosteric compounds) regulate the c-Abl kinase through different mechanisms. NMR studies show that a c-Abl fragment (SH3-SH2-linker-SH1) adopts different conformational states upon binding to each inhibitor. This supports an unconventional use for allosteric compounds to unraveling physiological c-Abl signaling circuits.

Keywords: c-Abl signaling motifs, stress responses, allosteric compounds

\section{INTRODUCTION}

Proteomics has revealed a rather complex picture underlying cellular signaling circuits. Recent studies have indicated an extensive overlap between diverse cellular responses. DNA damage-induced stress response overlaps with pathogen infection response and with heat stress in intact animals (Caenorhabditis elegans; Ermolaeva et al., 2013). Signaling connections between DNA damage, stress response, and aging remain elusive in other intact organisms (Gartner and Akay, 2013). Yet, evidence from Ermolaeva et al. (2013) supports a model of an integrated signaling network at the interface of various cell stress routes.

We have discussed about the aberrant $\mathrm{c}$-Abl signaling in the molecular events at the interface of oxidative stress metabolic regulation, protein aggregation, and DNA damage in neurons (Gonfloni et al., 2012). We have proposed that various stress responses seem to rely on a small set of recurring c-Abl-mediated regulatory circuits (Gonfloni et al., 2012). An emerging theme in neuronal diseases is the aberrant interplay between c-Abl phosphorylation of transcription factors, adaptors, modifiers/enzymes, and ubiquitin-mediated signaling responses (Gonfloni et al., 2012, Ciccone et al., 2013).

In this perspective, I will discuss how modulation of c-Abl, through small molecule allosteric inhibitors/ligands could be exploited to tackle the interface of $\mathrm{c}-\mathrm{Abl}$ signaling circuits.

\section{SURFING THE CELL SIGNALING CIRCUITS}

Cell metabolism and homeostasis rely on signaling networks of interacting proteins. Posttranslational modifications (PTMs) are crucial for the network. Colocalization of the binding partners converts protein interactions into functional consequences
(Kuriyan and Eisenberg, 2007). Crosstalk and interplay between different PTMs give rise to a versatile, rich, and dynamic framework of signaling circuits. Negative (or positive) feedback loops control the amplitude of signaling pathway and the sustained activation in time, conveying signals for irreversible decisions of the cell. A crucial issue for understanding cell signaling is to define how PTMs control changes in metabolism and homeostasis. A simple way is to consider protein domains as basic units of cell signaling (Kuriyan and Cowburn, 1997). Cells may use modular binding motifs like a broad device dedicated to the selective recognition of PTMs (Seet et al., 2006). However, complex biochemical responses can be only achieved in the context of multidomain proteins or multiprotein complexes. Of note, PTMs can also induce a new conformational state that in turn promotes an allosteric regulation of the targeted protein. An example of such an allosteric modulation is the phosphorylation of the activation loop of Src tyrosine kinases. This phosphorylation promotes the productive configuration of the catalytic site. By this mechanism, Src activity (i.e., a productive conformation of the active site in the catalytic domain) also controls the availability of the regulatory domains (SH3-linker; Gonfloni et al., 2000). This effect in turn promotes selective binding/recruitment in multiprotein complexes.

Posttranslational modifications are dynamic and necessary for assembling a temporary platform of local signaling circuits. PTMs work as an allosteric device both for the modified protein and for the assembly/(or reshaping?) of multiprotein complexes. Enzymes are often "switchable," with their activities controlled by many targets/effectors. The tyrosine kinases are themselves regulated by phosphorylation through various allosteric mechanisms. 
Non-receptor tyrosine kinases (RTKs) have a conserved catalytic domain (kinase domain $=\mathrm{SH} 1$ ), auto-inhibited by the binding of regulatory domains ( $\mathrm{SH} 2, \mathrm{SH} 3)$. Such an allosteric regulation links the enzymatic activity of the kinase with the colocalization of its substrate. Allosteric auto-regulation seems to be a recurring feature in cell signaling (Liu and Nussinov, 2013). Protein domains with enzymatic activity (acting as modifiers/writers) are often in tandem with the binding motifs devoted to recognition (acting as readers) of the same modification. This concept is also well substantiated by ubiquitin-mediated signaling. Ubiquitin represents a transferable interaction domain recognized by specialized binding motifs (ubiquitin binding domains, UBDs). Monoubiquitinated proteins often contain a UBD required for their auto-regulation (Seet et al., 2006).

\section{C-AbI IS AN ALLOSTERIC SIGNALING SWITCH FOR VARIOUS CELL RESPONSES}

Non-receptor Abl tyrosine kinases regulate a diverse range of cellular signaling paths. Recent reviews have discussed both the biological functions of the mammalian c-Abl tyrosine kinase (Colicelli, 2010, Wang, 2014) and the role of Abl family kinases in cancer (Greuber et al., 2013). It is beyond the scope of this review discussing these aspects. Interested readers are directed to several excellent reviews on this topic (Sirvent et al., 2008, Hossain et al., 2012, Greuber et al., 2013, Wang, 2014).

Here, I will recall the mechanisms of c-Abl auto-inhibition. The purpose is to highlight the effects of small molecule inhibitors on the conformation of $\mathrm{c}-\mathrm{Abl}$.

The Abl kinase family comprises two related proteins Abl1 (c-Abl) and Abl2 (Arg). Both kinases have redundant and unique roles due to their conserved sequence/domain structures. c-Abl and Arg have two different variants (1a and $1 \mathrm{~b}$ ). Both variants are ubiquitously expressed. Abl kinases share a conserved assembly of amino-terminal regulatory and catalytic domain ( $\mathrm{SH} 3-\mathrm{SH} 2-$ linker-SH1 domain). At the carboxyl terminus region, Abl kinases contain a filamentous (F)-actin-binding domain (ABD; Van Etten et al., 1994). c-Abl and Arg are less conserved in the middle region. So, Arg lacks of the three nuclear localization signal (NLS) motifs and localizes in the cytoplasm and in cell periphery (Miller et al., 2004). By contrast, c-Abl is present in the cytosol but also in organelles, such as the endoplasmic reticulum (ER) the mitochondria (Ito et al., 2001), or the nucleus (Wen et al., 1996). The diverse localization of c-Abl is modulated by PTMs (Yoshida et al., 2005). The formation of distinct multiprotein complexes is likely regulated by a dynamic spatial recruitment. Spatial distribution of $\mathrm{c}-\mathrm{Abl}$ is linked to the catalytic competence of the kinase. The latter is in constant equilibrium between low (fully inhibited) and high (fully activated) levels of activity (Hantschel and Superti-Furga, 2004). c-Abl signaling is not only dependent from the outcomes derived from its enzymatic kinase activity. But, it depends from dynamic recruitment of c-Abl into different protein complexes (and subcellular compartments). In vertebrates, its C-terminal F-ABD mediates actin binding, bundling and microtubule crosslinking (Bradley and Koleske, 2009). This has important consequences for cell adhesion, migration (Woodring et al., 2003), intracellular trafficking (Rotty et al., 2013), endocytosis (Lonskaya et al., 2013), autophagy (Yogalingam and Pendergast,
2008, Hebron et al., 2013b, Lonskaya et al., 2013). In Drosophila, $\mathrm{D}$-abl signaling is linked to actin dynamics and cell adhesion (reviewed by Lanier and Gertler, 2000, Hernandez et al., 2004). Recent evidence indicates that the D-abl kinase signaling regulates the Golgi complex architecture in neurons (Kannan et al., 2014). These data suggest that some of the effects of c-Abl signaling may arise from alterations of protein trafficking and secretion (Kannan et al., 2014). Kinase-independent functions of c-Abl have been already described (Henkemeyer et al., 1990, Chen et al., 2006). Evidence supports a kinase-independent function of Drosophila Abl for axonal guidance outcomes (O'Donnell and Bashaw, 2013). These results are consistent with a model for stepwise scaffolding and kinase functions of Abl in cell motility (Lapetina et al., 2009). Likely in a stepwise manner c-Abl promotes (or prevents) the formation of diverse signaling platforms within the cell. Specific outcomes rely on the full catalytic competence of the Abl kinase. The latter is due to local enrichment and/or a concomitant allosteric binding/removal of activators/adaptors/coinhibitors (as it occurs in the nucleus during apoptosis). Both local enrichment and expression/localization of binding partners (adaptors/co-inhibitors) depend from cellular context.

\section{ALLOSTERIC REGULATION OF c-AbI}

The auto-inhibited conformation of $\mathrm{c}-\mathrm{Abl}$ is controlled through $\mathrm{SH} 3-\mathrm{SH} 2-$ linker unit as in the Src family tyrosine kinases. In c$\mathrm{Src}$, the $\mathrm{SH} 2$ domain interacts with the C-terminal tail phosphotyrosine residue (Y527). By contrast, in $\mathrm{c}-\mathrm{Abl}$, the $\mathrm{SH} 2$ domain interacts more intimately with the large C-terminal lobe of the kinase domain ( $\mathrm{SH} 1)$. Interestingly, the tight interactions of the SH2-SH1 domain are induced by the binding of the myristoylated residues of the $\mathrm{N}$-terminal region into a hydrophobic pocket of the kinase (Figure 1; Nagar et al., 2003). c-Abl requires the $\mathrm{N}$-terminal myristoyl group (only present in Abllb variant) to help the proper SH3-SH2-linker docking and inhibition (Iacob et al., 2011, Corbi-Verge et al., 2013, de Oliveira et al., 2013). Allosteric inhibitory interactions for the Ablla variant are still poorly understood. Such interactions likely involve the binding of other inhibitors/adaptors. Small molecule compounds (GNF-2 and GNF-5) targeting the myristate pocket in the C-lobe of the

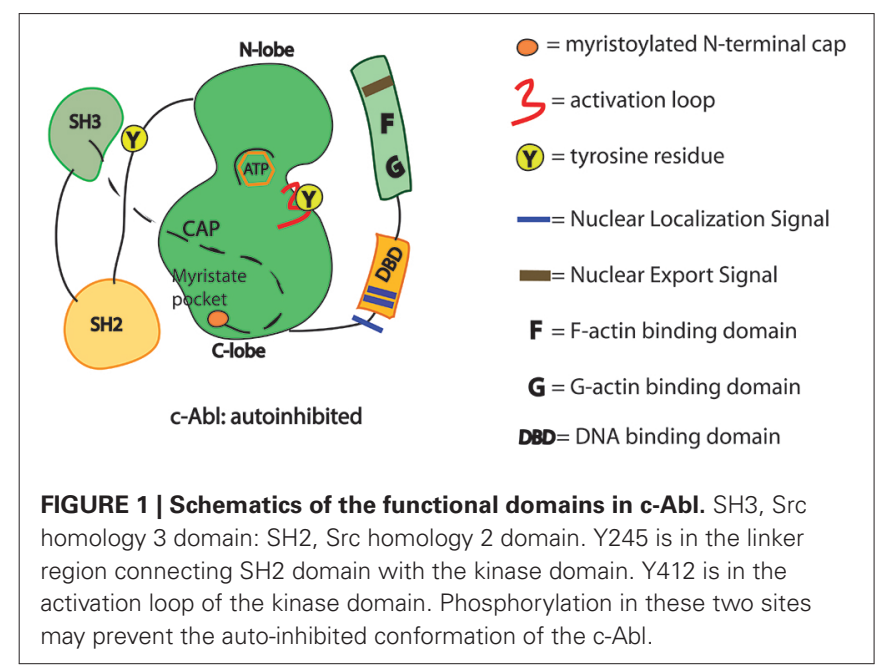


kinase domain do act as allosteric c-Abl inhibitors (Adrian et al., 2006, Fabbro et al., 2010, Zhang et al., 2010). The relevance of the myristoyl-binding pocket is further reinforced by the recent discovery of small-molecule c-Abl activators that dock into the same site (Yang et al., 2011, Hong et al., 2014). Upon c-Abl activation and removal of the allosteric interactions, the $\mathrm{SH} 2$ domain interacts with the N-terminal lobe of the kinase domain by using different surfaces of the SH2 domain (Hantschel, 2012). Compelling evidence indicates that the $\mathrm{SH} 2$ domain acts as a positive allosteric activator via the formation of an internal interface with the N-terminal lobe of kinase domain (Hantschel, 2012). Of note, the positioning of the $\mathrm{SH} 2$ domain facilitates multisite phosphorylation of substrates by c-Abl (Filippakopoulos et al., 2008, Grebien et al., 2011). However, alternative active states of c-Abl that do not require the $\mathrm{SH} 2 /$ kinase interface to function may occur when local clustering of c-Abl kinase core is sufficient for triggering transphosphorylation of the activation loop. In these circumstances the $\mathrm{SH} 2$ domain displacement from the back of the kinase domain is dispensable (Panjarian et al., 2013a,b). In short, the multidomain kinases like c-Abl can assume various conformational states and take more than one path to activation.

\section{EMERGING CONCEPTS FROM THE SOLUTION CONFORMATIONS OF c-AbI}

Recent structural studies using NMR in combination with small angle X-ray scattering (SAXS) of a c-Abl fragment (SH3-SH2linker-SH1 domains) provide the first structural information of apo form of $\mathrm{c}-\mathrm{Abl}$ in the absence of small molecule inhibitors (Skora et al., 2013). The apo form of c-abl adopts the "closed" conformation with the $\mathrm{SH} 3-\mathrm{SH} 2$ regulatory unit engaged with the kinase domain. However, addition of Imatinib (an ATPcompetitive inhibitor) induces both a large structural rearrangement of the kinase domain and the detachment of the $\mathrm{SH} 3-\mathrm{SH} 2$ regulatory unit from the kinase domain leading to the formation of an "open" inactive state, where the ATP binding site is not accessible. In contrast to Imatinib, addition of the myristoyl pocket ligand GNF-5 to apo c-Abl induces only limited local changes around the myristoyl-binding pocket and keeps the $\mathrm{SH} 3-$ $\mathrm{SH} 2$ regulatory unit in the "closed" state. Addition of GNF-5 to the "open" inactive state (c-Abl in complex with Imatinib) restores the "closed" inactive conformation (Skora et al., 2013). Under physiological conditions the "open" and "closed" conformations of $\mathrm{c}-\mathrm{Abl}$ may be in equilibrium, which can be altered by the presence of specific inhibitors (ATP-competitive and/or allosteric ones).

It has been proposed that the ABD may stabilize the autoinhibited conformation of the kinase by binding to F-actin (Woodring et al., 2003). Interestingly, the inhibitory effect of $\mathrm{F}$-actin requires the $\mathrm{SH}$-kinase domain interaction to maintain the auto-inhibited conformation (Woodring et al., 2003). Small molecule inhibitors may induce a structural remodeling of the auto-inhibited conformation. This in turn may perturb domain interactions and consequently impinge on adaptor/effector/substrate binding, modulating c-Abl signaling dynamics. Cells treated with Imatinib show a profound change in the shape and a more rapid migration when plated on collagen-coated substrates (Chen et al., 2013). GNF-2 promotes a translocation of c-Abl to the endoplasmic reticulum (Choi et al., 2009). It is tempting to consider that GNF-2 promotes a dynamic recruitment of c-Abl into different subcellular compartments and protein contexts. A timely relocalization of c-Abl/GNF-2 complex in a specific subcellular compartment may induce per se a signaling circuitry.

An unproductive conformation ("open" inactive state) of the catalytic site induced by Imatinib may promote the availability of the regulatory domains $(\mathrm{SH} 3-\mathrm{SH}$-linker-ABD) with profound effects on c-Abl-interactome.

Molecular switches like c-Abl have modular domains required for their assembly into multiprotein complexes. Yet, c-Abl has also a modifier/kinase domain to regulate scaffold/signaling dynamics. The challenge now is to understand how such a complex signaling assembly is regulated in time and space (Hossain et al., 2012). Of note, both local enrichment and expression/localization of binding partners (adaptors/co-inhibitors) are dictated from the cell type and signaling context.

\section{ABERRANT c-AbI SIGNALING}

The c-Abl kinase was early discovered as the oncogene in the Abelson murine leukemia virus (Goff et al., 1980) and then associated with human leukemias (Ben-Neriah et al., 1986). Several reports have indicated that c-Abl is a substrate and an activator of RTK. This bidirectional activation contributes to robust and persistent RTK signaling (Bromann et al., 2004). Cancer cells, expressing high levels of c-Abl, become dependent from its catalytic activity for growth and viability (reviewed in Greuber et al., 2013). On the other hand, in neurons aberrant c-Abl activation causes hyperphosphorylation, misfolding, and protein aggregation of tau protein, or alpha-synuclein. Such effects are considered hallmarks of neurodegenerative diseases (Ciccone et al., 2013, Tenreiro et al., 2014).

\section{c-AbI SIGNALING MEETS UBIQUITIN-MEDIATED RESPONSE}

Cell signaling relies on PTMs for its regulation. The interplay and the crosstalk between phosphorylation and ubiquitination represent a recurrent theme in cell signaling (Hunter, 2007). We have discussed about some connections occurring between c-Abl phosphorylation and ubiquitin-mediated signaling in DNA damage response (Maiani et al., 2011). Kinase phosphorylation/activation often triggers ubiquitination. Activated forms of c-Abl are more unstable than wild-type (Echarri and Pendergast, 2001).

Compelling evidence indicates that c-Abl modulates the degradation of two proteins implicated in the pathogenesis of Parkinson's disease (Mahul-Mellier et al., 2014). A specific inhibitor of c-Abl like Nilotinib, used for leukemia treatment, promotes autophagic degradation of $\alpha$-synuclein while protecting neurons (Hebron et al., 2013a, Lonskaya et al., 2014). Interestingly, Nilotinib-induced autophagic changes increase endogenous Parkin level and ubiquitination, favoring amyloid clearance (Lonskaya et al., 2014). Taken together the data indicate that small molecule c-Abl inhibitors (ATP-competitive) may modulate the interplay between $\mathrm{c}-\mathrm{Abl}$ and ubiquitin-mediated signaling. Convincing evidence indicates that c-Abl-mediated phosphorylation directly regulates the activity of some substrate E3 ligases (Zuckerman et al., 2009, Chan et al., 2013). In addition, negative regulation of E3 ligase activity by c-Abl can require a specific 
recruitment of c-Abl into a complex with adaptor molecules, necessary for proper localization (Skouloudaki and Walz, 2012). Of note, tyrosine phosphorylation of Parkin on Y143 inhibits its E3 ligase activity leading to an accumulation of Parkin substrates (Ko et al., 2010). On the contrary, Imatinib treatment restores the E3 ligase activity of Parkin and its protective function. Interestingly, administration of Nilotinib has reduced the c-Abl activation and the levels of the Parkin substrate (PARIS) without preventing tyrosine phosphorylation of Parkin and accumulation of the Parkin substrate AIMP2. This suggests that the protective effect of Nilotinib may be in part Parkin-independent or related to the pharmacodynamics properties of Nilotinib (Karuppagounder et al., 2014). Of note, Nilotinib belongs to a second generation of inhibitor, ATP-competitive like Imatinib. It is more potent $(>20$ fold), exhibiting activity toward the majority of Imatinib-resistant mutations. The majority of Nilotinib-c-Abl interactions overlap with those described in the Imatinib-c-Abl complex. However, Nilotinib binds many of mutants resistant to Imatinib and is less sensitive to mutations of the C-lobe of the kinase (Reddy and Aggarwal, 2012). This may reflect that Nilotinib induces a dynamic rearrangement in the catalytic domain, attenuating the effects of mutations on the auto-inhibited conformation.

\section{CONCLUSION}

Compelling evidence indicates the physiological relevance of the interface between $\mathrm{c}-\mathrm{Abl}$ signaling and stress response, metabolic regulation mediated by transcription factors (Gonfloni et al., 2012). A small molecule that binds to the myristate binding pocket in the C-lobe of the Abl kinase was shown to inhibit BcrAbl (Zhang et al., 2010). This result indicates a functional connection between the myristate pocket and the kinase active site. Data from hydrogen exchange mass spectrometry indicate that binding of GNF-2/GNF-5 induces a dynamic conformation of residues near Thr315 that allows ATP-competitive inhibitors to tolerate the isoleucine at this position (Zhang et al., 2010). However, it remains still elusive how changes in the myristate pocket are communicated to the ATP binding site of the kinase. Molecular dynamic (MD) simulations (Fallacara et al., 2014) and emerging evidence from recent structural studies using NMR indicate that c-Abl may assume different conformational states in presence with different small molecule inhibitors (Skora et al., 2013). Together these data indicate that GNF-2 binding induces a more compact conformation of SH2-kinase domain interface of c-Abl. Therefore allosteric ligands for myristoyl pocket may be valuable tools for tackling the interface of c-Abl signaling. They could represent a way to attenuate the enzymatic activity while impinging on critical $\mathrm{SH} 2$ domain interactions. This in turn may rewire downstream signaling circuits and/or pathways. Recent evidence on the use of GNF-2 in vivo supports such a model (Maiani et al., 2012). c-Abl interacts with a large number of proteins (up to now more than 100) most of them are also c-Abl substrates (85\%; Colicelli, 2010), in line with the idea that substrates can work as allosteric activators of the kinase. A better understanding of the spatiotemporal regulation of c-Abl signaling may allow us to modulate c-Abl signaling into specific subcellular compartments, with important consequences for cell homeostasis. These studies will take advantage from small allosteric compounds/activators as tools to investigate the biological functions of c-Abl (Hong et al., 2014). Surely, a detailed understanding of c-Abl functions will help to develop combined targeted therapies in order to rewire the physiological regulatory circuits in cancer cells and in aged neurons.

\section{ACKNOWLEDGMENTS}

This work was supported by AIRC grant (IG grant 2011 no. 11344) to Stefania Gonfloni. I thank all my collaborators (past and present) for stimulating discussions.

\section{REFERENCES}

Adrian, F. J., Ding, Q., Sim, T., Velentza, A., Sloan, C., Liu, Y., et al. (2006). Allosteric inhibitors of Bcr-abl-dependent cell proliferation. Nat. Chem. Biol. 2, 95-102. doi: 10.1038/nchembio760

Ben-Neriah, Y., Daley, G. Q., Mes-Masson, A. M., Witte, O. N., and Baltimore, D. (1986). The chronic myelogenous leukemia-specific P210 protein is the product of the bcr/abl hybrid gene. Science 233, 212-214. doi: 10.1126/science.3460176

Bradley, W. D., and Koleske, A. J. (2009). Regulation of cell migration and morphogenesis by Abl-family kinases: emerging mechanisms and physiological contexts. J. Cell Sci. 122, 3441-3454. doi: 10.1242/jcs.039859

Bromann, P. A., Korkaya, H., and Courtneidge, S. A. (2004). The interplay between Src family kinases and receptor tyrosine kinases. Oncogene 23, 7957-7968. doi: 10.1038/sj.onc.1208079

Chan, A. L., Grossman, T., Zuckerman, V., Campigli Di Giammartino, D., Moshel, O., Scheffner, M., et al. (2013). c-Abl phosphorylates E6AP and regulates its E3 ubiquitin ligase activity. Biochemistry 52, 3119-3129. doi: 10.1021/bi301710c

Chen, X., Zhang, J., Lee, J., Lin, P. S., Ford, J. M., Zheng, N., et al. (2006). A kinaseindependent function of $\mathrm{c}-\mathrm{Abl}$ in promoting proteolytic destruction of damaged DNA binding proteins. Mol. Cell 22, 489-499. doi: 10.1016/j.molcel.2006.04.021

Chen, Z., Lessey, E., Berginski, M. E., Cao, L., Li, J., Trepat, X., et al. (2013). Gleevec, an $\mathrm{Abl}$ family inhibitor, produces a profound change in cell shape and migration. PLoS ONE 8:e52233. doi: 10.1371/journal.pone.0052233

Choi, Y., Seeliger, M. A., Panjarian, S. B., Kim, H., Deng, X., Sim, T., et al. (2009). $N$-myristoylated c-Abl tyrosine kinase localizes to the endoplasmic reticulum upon binding to an allosteric inhibitor. J. Biol. Chem. 284, 29005-29014. doi: 10.1074/jbc.M109.026633

Ciccone, S., Maiani, E., Bellusci, G., Diederich, M., and Gonfloni, S. (2013). Parkinson's disease: a complex interplay of mitochondrial DNA alterations and oxidative stress. Int. J. Mol. Sci. 14, 2388-2409. doi: 10.3390/ijms14022388

Colicelli, J. (2010). ABL tyrosine kinases: evolution of function, regulation, and specificity. Sci. Signal. 3, re6. doi: 10.1126/scisignal.3139re6

Corbi-Verge, C., Marinelli, F., Zafra-Ruano, A., Ruiz-Sanz, J., Luque, I., and Faraldo-Gomez, J. D. (2013). Two-state dynamics of the SH3-SH2 tandem of Abl kinase and the allosteric role of the N-cap. Proc. Natl. Acad. Sci. U.S.A. 110, E3372-E3380. doi: 10.1073/pnas.1303966110

de Oliveira, G. A., Pereira, E. G., Ferretti, G. D., Valente, A. P., Cordeiro, Y., and Silva, J. L. (2013). Intramolecular dynamics within the N-Cap-SH3-SH2 regulatory unit of the $\mathrm{c}-\mathrm{Abl}$ tyrosine kinase reveal targeting to the cellular membrane. J. Biol. Chem. 288, 28331-28345. doi: 10.1074/jbc.M113.500926

Echarri, A., and Pendergast, A. M. (2001). Activated c-Abl is degraded by the ubiquitin-dependent proteasome pathway. Curr. Biol. 11, 1759-1765. doi: 10.1016/S0960-9822(01)00538-3

Ermolaeva, M. A., Segref, A., Dakhovnik, A., Ou, H. L., Schneider, J. I., Utermohlen, O., et al. (2013). DNA damage in germ cells induces an innate immune response that triggers systemic stress resistance. Nature 501, 416-420. doi: 10.1038 /nature 12452

Fabbro, D., Manley, P. W., Jahnke, W., Liebetanz, J., Szyttenholm, A., Fendrich, G., et al. (2010). Inhibitors of the Abl kinase directed at either the ATP- or myristate-binding site. Biochim. Biophys. Acta 1804, 454-462. doi: 10.1016/j.bbapap.2009.12.009

Fallacara, A. L., Tintori, C., Radi, M., Schenone, S., and Botta, M. (2014). Insight into the allosteric inhibition of Abl kinase. J. Chem. Inf. Model. 54, 1325-1338. doi: 10.1021/ci500060k

Filippakopoulos, P., Kofler, M., Hantschel, O., Gish, G. D., Grebien, F., Salah, E., et al. (2008). Structural coupling of SH2-kinase domains links Fes and 
Abl substrate recognition and kinase activation. Cell 134, 793-803. doi: 10.1016/j.cell.2008.07.047

Gartner, A., and Akay, A. (2013). Stress response: anything that doesn't kill you makes you stronger. Curr. Biol. 23, R1012-R1014. doi: 10.1016/ j.cub.2013.09.036

Goff, S. P., Gilboa, E., Witte, O. N., and Baltimore, D. (1980). Structure of the Abelson murine leukemia virus genome and the homologous cellular gene: studies with cloned viral DNA. Cell 22, 777-785. doi: 10.1016/0092-8674(80) 90554-1

Gonfloni, S., Maiani, E., Di Bartolomeo, C., Diederich, M., and Cesareni, G. (2012). Oxidative stress, DNA damage, and c-Abl signaling: at the crossroad in neurodegenerative diseases? Int. J. Cell Biol. 2012, 683097. doi: 10.1155/2012/683097

Gonfloni, S., Weijland, A., Kretzschmar, J., and Superti-Furga, G. (2000). Crosstalk between the catalytic and regulatory domains allows bidirectional regulation of Src. Nat. Struct. Biol. 7, 281-286. doi: 10.1038/74041

Grebien, F., Hantschel, O., Wojcik, J., Kaupe, I., Kovacic, B., Wyrzucki, A. M., et al. (2011). Targeting the SH2-kinase interface in Bcr-Abl inhibits leukemogenesis. Cell 147, 306-319. doi: 10.1016/j.cell.2011.08.046

Greuber, E. K., Smith-Pearson, P., Wang, J., and Pendergast, A. M. (2013). Role of ABL family kinases in cancer: from leukaemia to solid tumours. Nat. Rev. Cancer 13, 559-571. doi: $10.1038 / \mathrm{nrc} 3563$

Hantschel, O. (2012). Structure, regulation, signaling, and targeting of abl kinases in cancer. Genes Cancer 3, 436-446. doi: 10.1177/1947601912458584

Hantschel, O., and Superti-Furga, G. (2004). Regulation of the c-Abl and Bcr-Abl tyrosine kinases. Nat. Rev. Mol. Cell Biol. 5, 33-44. doi: 10.1038/nrm1280

Hebron, M. L., Lonskaya, I., and Moussa, C. E. (2013a). Nilotinib reverses loss of dopamine neurons and improves motor behavior via autophagic degradation of alpha-synuclein in Parkinson's disease models. Hum. Mol. Genet. 22, 3315-3328. doi: $10.1093 / \mathrm{hmg} / \mathrm{ddt} 192$

Hebron, M. L., Lonskaya, I., and Moussa, C. E. (2013b). Tyrosine kinase inhibition facilitates autophagic SNCA/alpha-synuclein clearance. Autophagy 9, 12491250. doi: $10.4161 /$ auto. 25368

Henkemeyer, M., West, S. R., Gertler, F. B., and Hoffmann, F. M. (1990). A novel tyrosine kinase-independent function of Drosophila abl correlates with proper subcellular localization. Cell 63, 949-960. doi: 10.1016/0092-8674(90)90498-4

Hernandez, S. E., Krishnaswami, M., Miller, A. L., and Koleske, A. J. (2004). How do Abl family kinases regulate cell shape and movement? Trends Cell Biol. 14, 36-44. doi: 10.1016/j.tcb.2003.11.003

Hong, X., Cao, P., Washio, Y., Simpson, G., Campobasso, N., Yang, J., et al. (2014). Structure-guided optimization of small molecule c-Abl activators. J. Comput. Aided Mol. Des. 28, 75-87. doi: 10.1007/s10822-014-9731-5

Hossain, S., Dubielecka, P. M., Sikorski, A. F., Birge, R. B., and Kotula, L. (2012). Crk and ABIl: binary molecular switches that regulate abl tyrosine kinase and signaling to the cytoskeleton. Genes Cancer 3, 402-413. doi: $10.1177 / 1947601912460051$

Hunter, T. (2007). The age of crosstalk: phosphorylation, ubiquitination, and beyond. Mol. Cell 28, 730-738. doi: 10.1016/j.molcel.2007.11.019

Iacob, R. E., Zhang, J., Gray, N. S., and Engen, J. R. (2011). Allosteric interactions between the myristate- and ATP-site of the Abl kinase. PLoS ONE 6:e15929. doi: 10.1371/journal.pone.0015929

Ito, Y., Pandey, P., Mishra, N., Kumar, S., Narula, N., Kharbanda, S., et al. (2001). Targeting of the c-Abl tyrosine kinase to mitochondria in endoplasmic reticulum stress-induced apoptosis. Mol. Cell. Biol. 21, 6233-6242. doi: 10.1128/MCB.21.18.6233-6242.2001

Kannan, R., Kuzina, I., Wincovitch, S., Nowotarski, S. H., and Giniger, E. (2014). The Abl/enabled signaling pathway regulates Golgi architecture in Drosophila photoreceptor neurons. Mol. Biol. Cell 25, 2993-3005. doi: 10.1091/mbc.E1402-0729

Karuppagounder, S. S., Brahmachari, S., Lee, Y., Dawson, V. L., Dawson, T. M., and Ko, H. S. (2014). The c-Abl inhibitor, nilotinib, protects dopaminergic neurons in a preclinical animal model of Parkinson's disease. Sci. Rep. 4, 4874. doi: $10.1038 /$ srep 04874

Ko, H. S., Lee, Y., Shin, J. H., Karuppagounder, S. S., Gadad, B. S., Koleske, A. J., et al. (2010). Phosphorylation by the c-Abl protein tyrosine kinase inhibits Parkinson's ubiquitination and protective function. Proc. Natl. Acad. Sci. U.S.A. 107, 16691-16696. doi: 10.1073/pnas.1006083107

Kuriyan, J., and Cowburn, D. (1997). Modular peptide recognition domains in eukaryotic signaling. Annu. Rev. Biophys. Biomol. Struct. 26, 259-288. doi: 10.1146/annurev.biophys.26.1.259
Kuriyan, J., and Eisenberg, D. (2007). The origin of protein interactions and allostery in colocalization. Nature 450, 983-990. doi: 10.1038/nature 06524

Lanier, L. M., and Gertler, F. B. (2000). From Abl to actin: Abl tyrosine kinase and associated proteins in growth cone motility. Curr. Opin. Neurobiol. 10, 80-87. doi: 10.1016/S0959-4388(99)00058-6

Lapetina, S., Mader, C. C., Machida, K., Mayer, B. J., and Koleske, A. J. (2009). Arg interacts with cortactin to promote adhesion-dependent cell edge protrusion. J. Cell Biol. 185, 503-519. doi: 10.1083/jcb.200809085

Liu, J., and Nussinov, R. (2013). The role of allostery in the ubiquitinproteasome system. Crit. Rev. Biochem. Mol. Biol. 48, 89-97. doi: 10.3109/10409238.2012.742856

Lonskaya, I., Hebron, M. L., Desforges, N. M., Franjie, A., and Moussa, C. E. (2013). Tyrosine kinase inhibition increases functional parkin-Beclin-1 interaction and enhances amyloid clearance and cognitive performance. EMBO Mol. Med. 5, 1247-1262. doi: 10.1002/emmm.201302771

Lonskaya, I., Hebron, M. L., Desforges, N. M., Schachter, J. B., and Moussa, C. E. (2014). Nilotinib-induced autophagic changes increase endogenous parkin level and ubiquitination, leading to amyloid clearance. J. Mol. Med. (Berl.) 92, 373386. doi: 10.1007/s00109-013-1112-3

Mahul-Mellier, A. L., Fauvet, B., Gysbers, A., Dikiy, I., Oueslati, A., Georgeon, S., et al. (2014). c-Abl phosphorylates alpha-synuclein and regulates its degradation: implication for alpha-synuclein clearance and contribution to the pathogenesis of Parkinson's disease. Hum. Mol. Genet. 23, 2858-2879. doi: 10.1093/hmg/ddt674

Maiani, E., Di Bartolomeo, C., Klinger, F. G., Cannata, S. M., Bernardini, S., Chateauvieux, S., et al. (2012). Reply to: cisplatin-induced primordial follicle oocyte killing and loss of fertility are not prevented by imatinib. Nat. Med. 18, 1172-1174. doi: $10.1038 / \mathrm{nm} .2852$

Maiani, E., Diederich, M., and Gonfloni, S. (2011). DNA damage response: the emerging role of c-Abl as a regulatory switch? Biochem. Pharmacol. 82, 12691276. doi: 10.1016/j.bcp.2011.07.001

Miller, A. L., Wang, Y., Mooseker, M. S., and Koleske, A. J. (2004). The Abl-related gene $(\mathrm{Arg})$ requires its F-actin-microtubule cross-linking activity to regulate lamellipodial dynamics during fibroblast adhesion. J. Cell Biol. 165, 407-419. doi: $10.1083 /$ jcb.200308055

Nagar, B., Hantschel, O., Young, M. A., Scheffzek, K., Veach, D., Bornmann, W., et al. (2003). Structural basis for the autoinhibition of c-Abl tyrosine kinase. Cell 112, 859-871. doi: 10.1016/S0092-8674(03)00194-6

O'Donnell, M. P., and Bashaw, G. J. (2013). Distinct functional domains of the Abelson tyrosine kinase control axon guidance responses to Netrin and Slit to regulate the assembly of neural circuits. Development 140, 2724-2733. doi: 10.1242/dev.093831

Panjarian, S., Iacob, R. E., Chen, S., Engen, J. R., and Smithgall, T. E. (2013a). Structure and dynamic regulation of Abl kinases. J. Biol. Chem. 288, 5443-5450. doi: $10.1074 /$ jbc.R112.438382

Panjarian, S., Iacob, R. E., Chen, S., Wales, T. E., Engen, J. R., and Smithgall, T. E. (2013b). Enhanced SH3/linker interaction overcomes Abl kinase activation by gatekeeper and myristic acid binding pocket mutations and increases sensitivity to small molecule inhibitors. J. Biol. Chem. 288, 6116-6129. doi: 10.1074/jbc.M112.431312

Reddy, E. P., and Aggarwal, A. K. (2012). The ins and outs of bcr-abl inhibition. Genes Cancer 3, 447-454. doi: 10.1177/1947601912462126

Rotty, J. D., Wu, C., and Bear, J. E. (2013). New insights into the regulation and cellular functions of the ARP2/3 complex. Nat. Rev. Mol. Cell Biol. 14, 7-12. doi: 10.1038/nrm3492

Seet, B. T., Dikic, I., Zhou, M. M., and Pawson, T. (2006). Reading protein modifications with interaction domains. Nat. Rev. Mol. Cell Biol. 7, 473-483. doi: $10.1038 / \mathrm{nrm} 1960$

Sirvent, A., Benistant, C., and Roche, S. (2008). Cytoplasmic signalling by the c-Abl tyrosine kinase in normal and cancer cells. Biol. Cell 100, 617-631. doi: $10.1042 / \mathrm{BC} 20080020$

Skora, L., Mestan, J., Fabbro, D., Jahnke, W., and Grzesiek, S. (2013). NMR reveals the allosteric opening and closing of Abelson tyrosine kinase by ATP-site and myristoyl pocket inhibitors. Proc. Natl. Acad. Sci. U.S.A. 110, E4437-E4445. doi: 10.1073/pnas. 1314712110

Skouloudaki, K., and Walz, G. (2012). YAP1 recruits c-Abl to protect angiomotin-like 1 from Nedd4-mediated degradation. PLoS ONE 7:e35735. doi: 10.1371/journal.pone.0035735 
Tenreiro, S., Eckermann, K., and Outeiro, T. F. (2014). Protein phosphorylation in neurodegeneration: friend or foe? Front. Mol. Neurosci. 7:42. doi: 10.3389/fnmol.2014.00042

Van Etten, R. A., Jackson, P. K., Baltimore, D., Sanders, M. C., Matsudaira, P. T., and Janmey, P. A. (1994). The COOH terminus of the c-Abl tyrosine kinase contains distinct F- and G-actin binding domains with bundling activity. J. Cell Biol. 124, 325-340. doi: 10.1083/jcb.124.3.325

Wang, J. Y. (2014). The capable ABL: what is its biological function? Mol. Cell. Biol. 34, 1188-1197. doi: 10.1128/MCB.01454-13

Wen, S. T., Jackson, P. K., and Van Etten, R. A. (1996). The cytostatic function of c-Abl is controlled by multiple nuclear localization signals and requires the p53 and $\mathrm{Rb}$ tumor suppressor gene products. EMBO J. 15, 15831595.

Woodring, P. J., Hunter, T., and Wang, J. Y. (2003). Regulation of F-actin-dependent processes by the Abl family of tyrosine kinases. J. Cell Sci. 116, 2613-2626. doi: $10.1242 /$ jcs.00622

Yang, J., Campobasso, N., Biju, M. P., Fisher, K., Pan, X. Q., Cottom, J., et al. (2011). Discovery and characterization of a cell-permeable, small-molecule c-Abl kinase activator that binds to the myristoyl binding site. Chem. Biol. 18, 177-186. doi: 10.1016/j.chembiol.2010.12.013

Yogalingam, G., and Pendergast, A. M. (2008). Abl kinases regulate autophagy by promoting the trafficking and function of lysosomal components. J. Biol. Chem. 283, 35941-35953. doi: 10.1074/jbc.M804543200

Yoshida, K., Yamaguchi, T., Natsume, T., Kufe, D., and Miki, Y. (2005). JNK phosphorylation of 14-3-3 proteins regulates nuclear targeting of c-Abl in the apoptotic response to DNA damage. Nat. Cell Biol. 7, 278-285. doi: 10.1038/ ncb 1228

Zhang, J., Adrian, F. J., Jahnke, W., Cowan-Jacob, S. W., Li, A. G., Iacob, R. E., et al. (2010). Targeting Bcr-Abl by combining allosteric with ATP-binding-site inhibitors. Nature 463, 501-506. doi: 10.1038/nature08675

Zuckerman, V., Lenos, K., Popowicz, G. M., Silberman, I., Grossman, T., Marine, J. C., et al. (2009). c-Abl phosphorylates Hdmx and regulates its interaction with p53. J. Biol. Chem. 284, 4031-4039. doi: 10.1074/jbc.M809211200

Conflict of Interest Statement: The author declares that the research was conducted in the absence of any commercial or financial relationships that could be construed as a potential conflict of interest.

Received: 07 June 2014; accepted: 25 October 2014; published online: 12 November 2014.

Citation: Gonfloni S (2014) Defying c-Abl signaling circuits through small allosteric compounds. Front. Genet. 5:392. doi: 10.3389/fgene.2014.00392

This article was submitted to Systems Biology, a section of the journal Frontiers in Genetics.

Copyright (C) 2014 Gonfloni. This is an open-access article distributed under the terms of the Creative Commons Attribution License (CC BY). The use, distribution or reproduction in other forums is permitted, provided the original author(s) or licensor are credited and that the original publication in this journal is cited, in accordance with accepted academic practice. No use, distribution or reproduction is permitted which does not comply with these terms. 